\title{
Investigation of West Nile Fever Seroprevalence and Associated Risk Factors among Horses in Egypt
}

Abdelfattah selim ( $\nabla$ abdelfattah.selim@fvtm.bu.edu.eg )

Banha University

Ameer Megahed

Banha University

Sahar Kandeel

Banha University

Abdullah Alanazi

Shaqra University

\section{Research Article}

Keywords: West Nile Fever, Serology, Risk factors, Horses

Posted Date: December 30th, 2020

DOl: https://doi.org/10.21203/rs.3.rs-135117/v1

License: (c) (1) This work is licensed under a Creative Commons Attribution 4.0 International License. Read Full License 


\section{Abstract}

Determination of the seroprevalence and risk factors associated with West Nile Fever (WNF) in horses is essential for adoption of effective prevention strategies. Our objective was therefore to determine the seroprevalence and identify the risk factors associated with West Nile virus (WNV) infection in the most densely horse populated provinces in Egypt. A cross-sectional study was conducted on 930 horses distributed over five provinces in the Nile Delta of Egypt in 2018. The randomly selected horses from geographical studied areas were serologically tested for WNF, and the horses' information was obtained from owners. Four variables (geographic location, breed, gender, and age) were used for risk analysis. A total of $156(16.8 \%)$ serum samples were serologically positive for WNV. The highest prevalence of WNV infection was between mixed breed (21.5\%), male (26.4\%) horses with age $\geq 15$ years $(68.1 \%)$. Age showed the highest risk for the infection with WNV ( $\mathrm{OR}=4.3,95 \% \mathrm{Cl} 3.0$ to 6.2$)$. Gender and breed also showed important risk factors for WNF infection in horses $(\mathrm{OR}=2.4,95 \% \mathrm{Cl} 1.6$ to $3.7 ; \mathrm{OR}=1.9,95 \% \mathrm{Cl}$ 1.2 to 2.8 , respectively). However, geographic location seems to have no impact on the seroprevalence of WNV infection among horses in the Nile Delta of Egypt. Our findings strongly recommend intensive surveillance and implementation of effective control and prevention strategies against WNF especially in male of mixed breed horses with ages $\geq 15$ years.

\section{Introduction}

West Nile Fever (WNF) is a zoonotic, widespread vector-borne infection caused by West Nile virus (WNV) that belongs to the family Flaviviridae ${ }^{1}$. The disease is listed by the World Organization for Animal Health (OIE) as notifiable disease that requiring the individuals and the member countries to report its occurrence. West Nile Virus maintained in the nature and spread across the country by cycling between as a biological vector and birds, the primary host, taking advantage of free-ranging birds and mosquitoes, and incidentally infects humans and horses that do not contribute to the spread or amplification of the virus $^{2,3}$. In Egypt, Culex antennatus is the major mosquito species responsible for transmission in the amplification cycle ${ }^{4}$. All over the world, more than 300 bird species may act as vertebrate hosts for WNV, and the infected migratory birds are thought to play the major role in the spread of the virus to the free areas ${ }^{5}$.

The WNV was first reported in 1937 in the West Nile region of Uganda and over the past decades, the virus became endemic in many African including the Middle East, European, and Asian countries ${ }^{6}$. Since the 1960's, Europe has reported sporadic cases and outbreaks of WNV in both human and horses. Surveys in parts of Europe and the Middle East have shown that up to a third of the tested horses have been exposed to the virus even with absence of the clinical disease ${ }^{7,8}$. In 1999, the WNV was first reported in the eastern United States where it caused severe epidemic of meningoencephalitis in New York City. Then, it spread throughout Canada, and Central America ${ }^{5}$. In the early 1950 s, WNV was first recorded in the Mediterranean basin, including Egypt and Israel, and equine WNV encephalomyelitis was first recorded in Egypt in 1959 4,9. Several outbreaks among equine populations was then sparked the 
importance of the disease and raise interest in predicting where and when the virus would appear next 4,10. However, few small-scale studies conducted to examine the prevalence of WNV infection among equine in Egypt.

Defining the risk factors of acquiring infection with WNV is a key component of successful prevention and control strategies and help in the decision of whether or not to vaccinate ${ }^{11}$. Intriguingly, animal related factors such as age and breed showed association with the seroprevalence of WNV infection among horses ${ }^{12}$. However, the effect of these factors is still controversy and need further investigation. The main objective of this study was therefore to investigate the seroprevalence of WNV infection among horses raised in the Nile Delta of Egypt, as well as to determine the risk factors associate with the infected horses.

\section{Results}

\subsection{Seroprevalence of WNV}

The seroprevalence of BLV was determined in 930 serum samples obtained from three different breeds of horse (Arabian, Thoroughbred, and Mixed) located in 5 provinces in the Nile Delta of Egypt (KF, GB, MF, Qal, and GZ) at age ranged from 2 to 16 years. The distribution of horses based on the risk factors was illustrated in Table 1. 
Table 1

Descriptive analysis of variables used to predict the seroprevalence of West Nile virus infection in equine of the Nile Delta of Egypt.

\begin{tabular}{|llll|}
\hline Variable & Category & No. of horse & Distribution (\%) \\
\hline \multirow{5}{*}{ Governate } & Kafr-El-Sheikh & 160 & 17.2 \\
\cline { 2 - 4 } & Gharbia & 60 & 6.5 \\
\cline { 2 - 4 } & Menofia & 250 & 26.9 \\
\cline { 2 - 4 } & Qalyoubia & 130 & 14.0 \\
\cline { 2 - 4 } Breed & Giza & 330 & 35.5 \\
\cline { 2 - 4 } & Arabian & 300 & 32.3 \\
\cline { 2 - 4 } Gender & Thoroughbred & 351 & 37.7 \\
\cline { 2 - 4 } & Mixed & 279 & 30.0 \\
\cline { 2 - 4 } & Male & 500 & 53.8 \\
\cline { 2 - 4 } Age (year) & Female & 300 & 32.3 \\
\cline { 2 - 4 } & Gelding & 130 & 14.9 \\
\cline { 2 - 4 } & 2.5 & 29 & 3.1 \\
\cline { 2 - 4 } & $2.5-<5.0$ & 167 & 18.0 \\
\hline $5.0-<10$ & 463 & 49.8 \\
\hline $10.0-<15.0$ & 203 & 21.8 \\
\hline & $\geq 15.0$ & 68 & 7.31 \\
\hline
\end{tabular}

The total seroprevalence of WNF in this study is $16.8 \%$. The seroprevalence of WNF was non-significant differed between localities under the study. Menofia province showed the highest seroprevalence of WNF (21.5\%), followed by GB (17.2\%), GZ (16.7\%), KF (16.4\%), and QL (13.1\%) as shown in Table 2 and Fig. 1. The distribution of WNV-positive horses was differed between age $(P<0.001)$, gender $(P<0.001)$, and breed $(P<0.01$; Table 2$)$. 
Table 2

Univariable logistic regression analysis of the association of horse-level West Nile virus infection with different risk factors in the Nile Delta of Egypt

\begin{tabular}{|c|c|c|c|c|c|}
\hline Variable & Category & No. of horse & No. positive & Prevalence (\%) & $P$-value \\
\hline \multirow[t]{5}{*}{ Governate } & Kafr-El-Sheikh & 160 & 54 & 16.4 & \multirow[t]{5}{*}{0.768} \\
\hline & Gharbia & 60 & 43 & 17.2 & \\
\hline & Menofia & 250 & 28 & 21.5 & \\
\hline & Qalyoubia & 130 & 21 & 13.1 & \\
\hline & Giza & 330 & 10 & 16.7 & \\
\hline \multirow[t]{3}{*}{ Breed } & Arabian & 300 & 40 & 13.3 & \multirow[t]{3}{*}{0.005} \\
\hline & Thoroughbred & 351 & 54 & 15.4 & \\
\hline & Mixed & 279 & 62 & 22.2 & \\
\hline \multirow[t]{3}{*}{ Gender } & Male & 500 & 132 & 26.4 & \multirow[t]{3}{*}{$<0.001$} \\
\hline & Female & 300 & 12 & 4.0 & \\
\hline & Gelding & 130 & 12 & 9.2 & \\
\hline \multirow[t]{5}{*}{ Age (year) } & $<2.5$ & 29 & 0 & 0.0 & \multirow[t]{5}{*}{$<0.001$} \\
\hline & $2.5-<5.0$ & 167 & 8 & 4.8 & \\
\hline & $5.0-<10.0$ & 463 & 31 & 6.7 & \\
\hline & $10.0-<15.0$ & 203 & 75 & 37.0 & \\
\hline & $\geq 15.0$ & 68 & 42 & 61.8 & \\
\hline
\end{tabular}

The results of this study showed moderate associations between the seroprevalence of WNV infection and age (Phi Coefficient and Cramer's $V=0.56$ ), and weak association with gender $(0.28)$. However, the Phi Coefficient and Cramer's V of 0.10 and 0.06 indicated no association between the WNF seroprevalence and bread and geographic location, respectively.

The stepwise logistic regression model indicated that age, gender, and breed were significant risk factors for WNV infected horse (Table 3). Geriatric horses above 15 years had greater number odds for seropositivity of WNF ( $\mathrm{OR}=4.3,95 \% \mathrm{Cl} 3.0$ to 6.2 ; Fig. 2), where the horses with age of 15 years increased risk $(90 \%)$ of being seropositive for WNF and interestingly the probability of risk increases with age (Fig. 3). Male horses and mixed breed are also at a high risk for WNV infection (OR $=2.4,95 \% \mathrm{Cl} 1.6$ to $3.7 ; \mathrm{OR}=1.9,95 \% \mathrm{Cl} 1.2$ to 2.8 , respectively; Fig. 2,3). However, geographic location was not associated with increased risk of being seropositive for $\mathrm{WNV}(\mathrm{OR}=0.9,95 \% \mathrm{Cl}=0.8-1.1$; Fig. 2,3). 
Table 3

Multiple stepwise logistic regression analysis of variables associated with horses that are seropositive to West Nile virus in the Nile Delta of Egypt

\begin{tabular}{|llllll|}
\hline Variable & Estimated value & SE & $P$-value & OR & $95 \% \mathrm{Cl}_{\mathrm{OR}}$ \\
\hline Intercept & -8.39 & 0.98 & $<0.001$ & - & - \\
\hline Age & 1.46 & 0.19 & $<0.001$ & 4.3 & $3.0-6.2$ \\
\hline Gender & 0.62 & 0.22 & $<0.001$ & 2.4 & $1.6-3.7$ \\
\hline Breed & 0.89 & 0.21 & 0.005 & 1.9 & $1.2-2.8$ \\
\hline Governate & -0.43 & 0.12 & 0.272 & 0.6 & $0.5-0.8$ \\
\hline
\end{tabular}

\section{Materials And Methods}

All procedures involving the handling and collection of samples from horses used in this study were approved by the ethical committee for Animal Experiment of Benha University. Approval ID: BUFVTM. The methods were performed in accordance with relevant guidelines and regulations.

\subsection{Study area}

This study was carried out in five provinces (Kafr Elsheikh, KF; Gharbia, GB; Menofia, MF; Qalyoubia, QL; and Giza, GZ) north of Egypt. These provinces are located at $38^{\circ} 18 \mathrm{~N}$ to $30^{\circ} 56 \mathrm{E}, 30.867^{\circ} \mathrm{N} 31.028^{\circ} \mathrm{E}$, $30.52^{\circ} \mathrm{N} 30.99^{\circ} \mathrm{E}, 30^{\circ} 25 \mathrm{~N}$ to $31^{\circ} 13 \mathrm{E}$ and $30^{\circ} 01^{\prime} \mathrm{N} 31^{\circ} 13^{\prime} \mathrm{E}$ as shown in Fig. 1. These provinces were selected as they are considered the most densely horse populated areas in Egypt, where the horses are mainly raising for horse-drawn carriages transport and horse-based tourism. The climate of the selected areas is dry summers and mild, wet winters that help in multiplication and distribution of the vectors.

\subsection{Animals and sample collection}

Adequate sample size was used for this study based on calculation using Cochran's formula ${ }^{13}$, as follow:

$$
n=Z^{2} \frac{p(1-p)}{e^{2}}
$$

where $\mathrm{n}$ is the sample size, $\mathrm{Z}$ is the statistic corresponding to level of confidence, $\mathrm{p}$ is expected prevalence, and e is precision (corresponding to effect size). The level of confidence was used is $95 \%$, and the expected prevalence used in this study was $15 \%$ based on the reported prevalence published in Zaher and Ahmed (2014). The precision (e) used in this study was $5 \%$ based on ${ }^{14}$. 
A total of 930 animals were screened for WNV during 2018. Blood samples were collected from 500 males, 300 females and 130 Gelding with age groups ranged from $<5$ to $>10$ years. The blood samples were collected from jugular vein using $20 \mathrm{G}$ needles and $10 \mathrm{~mL}$ blood collection tubes. The proposed puncture site was cleared of debris and swabbed with gauze containing 70\% isopropyl alcohol. Serum was collected after centrifugation of the blood samples at $1500 \mathrm{rpm} / \mathrm{min}$ for $10 \mathrm{~min}$. The serum samples were stored at $-20{ }^{\mathrm{C}} \mathrm{C}$ for serological testing.

\subsection{Serological testing using ELISA}

All serum samples were serologically testing for WNV using ID screen West Nile Competition ELISA kit (IDVet, Montpellier, France) according to the manufacturer's instructions.

\subsection{Statistical analysis}

The associations of WMF with different risk factors were evaluated using the Cochran-Armitage trend test using PROC FREQ of SAS ${ }^{15}$. The strength of associations was evaluated through Phi and Cramer's V value. Chi-square and stepwise forward multivariable logistic regression were used to identify the most important risk factor(s) associated with WNF. The $P$-values for entry into or removal from the logistic regression models were $<0.05$. The logistic model, fitted with WNF as the outcome variable (present: 1 , absent: 0 ), included fixed effects of the risk factors of breed (3 levels: Arabian, Thoroughbred, and Mixed), gender (3 levels: male, female, and gelding), age (5 levels: $<2.5,2.5-<5,5<10,10<15, \geq 15$ years), and geographic location ( 5 levels: KF, GB, MF, Qal, and GZ). The stepwise elimination process was stopped once all remaining variables were significantly $(P<0.05)$ contributing to the model. The fit of the multivariable logistic regression model was assessed using the Hosmer-Lemeshow goodness-of-fit test. A logistic regression model predicts the log odds (logit) for outcome as an additive function of the risk factors. The odds ratio was used as an approximate measure of relative risk (the likelihood of having WNF in animal with a given risk factor compared with animal without the risk factor). The $95 \%$ Confidence intervals $(\mathrm{Cl})$ for odds ratio estimates were obtained as described by Lemeshow and Hosmer (1984). Odds ratios greater than 1 indicate an increased risk of the outcome (WNF) with increasing value of risk factor and odds ratios less than 1 indicate a decreased risk of the outcome (WNF) with increasing value of risk factor (Lemeshow and Hosmer 1984). Statistical analyses were performed using SAS 9.4 (SAS Inc., Cary, NC).

\section{Discussion}

West Nile virus is a mosquito-borne pathogen of global public health importance. With the rapid global spread of WNV and the endemic state, WNV might spread in new geographical areas in Egypt. To the best of our knowledge, this is the first large-scale study investigated the WNV seroprevalence between horses and the associated risk factors in Egypt. Therefore, the results of this study provide updated information about the WNV seroprevalence and the associated risk factors that can be used as a guide for effective prevention strategies. The major advantages of the current study are: 1) broad context of many provinces, placing it amongst the few studies that have examined the seroprevalence of WNV infections 
in horses across the most densely equine populated areas in Egypt; and 2) large number of participating horses that reflects on the robustness of the association between variables. The main finding of this study is that the male mixed breed horses with ages $\geq 15 \mathrm{y}$ are more susceptible to WNV infection in Egypt.

West Nile virus circulating in Egypt since 1951s ${ }^{9}$. In Egypt, most of the earlier studies were focused on the investigation of WNV epidemiology in humans ${ }^{9,16,17}$. Recently, the epidemiological status of WNV infection among horses is receiving a growing attention in Egypt. Overall, the antibodies against WNV were detected in 156 out of 930 (16.7\%) examined horses. The reported seroprevalence rate concur with other rates reported in different countries, $15.08 \%$ in Poland ${ }^{18}$, and $15 \%$ in Portugal ${ }^{19}$. However, this rate is lower than that reported in surroundings, where the prevalence of WNV infection among horses in Israel is $39 \%{ }^{20}, 24.9 \%$ in Jordan ${ }^{21}, 26.8 \%$ in Algeria ${ }^{22}, 31.1 \%$ in Morocco ${ }^{23}, 31.6 \%$ in Turkey ${ }^{24}$, and $68.7 \%$ in Senegal ${ }^{22}$. In USA, the prevalence of WNV infection was $56.4 \%$ in $2003{ }^{25}$. In Europe, the European Centre for Disease Prevention and Control (ECDC) and the World Organization for Animal Health (OIE) declared a total of 86 human cases and 14 cases in horses ${ }^{26}$. The lower horse-level seroprevalence of WNV that reported in this study is might be due to low number of horse farms and most of the horses enrolled in this study are individual raising horses. This may decrease the chance of horse exposure to virus. Additionally, one of the main factors affecting the spreading of WNV infection is the environmental factors ${ }^{16}$. The higher temperature above $30{ }^{\circ} \mathrm{C}$ as in the Nile Delta of Egypt particularly in summer, and low rainfall during winter and spring were associated with reduction in the mosquito activity and decrease in its growth. Consequently, the spread of WNV among horses will be decreased because the propagation of WNV in mosquitoes is temperature dependent ${ }^{27}$. A negative association has been reported between the WNV infection in mosquitoes and WNV epidemics and the previous year's precipitation ${ }^{20,28-30}$. Other factors such as humidity, presence of local and migratory birds' settlements, and vegetation index have also significant contributions to the propagation of WNV ${ }^{31}$. Furthermore, that most of sample collected early summer and most of WNV infection occurs usually in late summer and fall ${ }^{21}$.

The results of this study didn't show difference in the seroprevalence of WNV infection between studied geographic regions in the Nile Delta of Egypt in agreement with earlier studies ${ }^{16}$. This is a sensible result because the similar geographic nature of the land in the five studied provinces that is characterized by flat low-lying areas. Consequently, the insect population density, the main transmission vector for BLV, are approximately similar in these provinces. Another possible reason for the non-significant difference in the seroprevalence of WNV infection among the studied geographical areas is that the equine trading between provinces is not common in Egypt.

The results of the current study showed marked increase in the risk of WNV infection with age suggests recurrent circulation of WNV. This result is consistent with earlier studies ${ }^{12,32,33}$. However, other studies didn't show any association between the seropositivity of WNV infection and age ${ }^{10,18,21}$. It has been reported that the older affected horses have been more likely to die from the WNV infection ${ }^{34-36}$. In 
humans, the median age of affected human is $63 \mathrm{y}$, suggesting the older people are more prone to acquire WNV infection and approximately 20 -fold increased risk at age $>60$ y for susceptibility to neurological involvement and retinopathy associated with severe disease ${ }^{32,33}$. The reason behind this positive relationship between seropositivity of WNV infection and age is unknown but the older horses > 10 years are might be immunocompromised animals, where aging is associated with a dysregulation of the immune system ${ }^{37}$. With age, alterations occur to adaptive immunity compounds and reduction in innate recognition and signaling resulting in increased susceptibility to WNV in elderly horse ${ }^{38,39}$.

The second risk factor for WNV infection reported in this study was the gender. Our findings come in accordance with Epp, et al. ${ }^{34}$ that found a higher seroprevalence of WNV infection among stallions than mare or gelding. This interesting finding has been reported in human where they reported a higher seroprevalence of WNV in male than female ${ }^{40}$. Additionally, a higher rate of hospitalization and a higher incidence of neuroinvasive disease was shown in WNV-infected males than WNV-infected females ${ }^{41}$. The reason behind this result is unclear but several human studies reported gender deference in the seroprevalence of WNV ${ }^{40,42}$. They suggest that gender may play an important role in sustaining WNV immunity. A marked difference was found in immune response against WNV infection between males and females as the infection progressed, with WNV-infected males exhibiting an altered cytokine response ${ }^{42}$. The difference in immune response to viral infection between males and females may be partly attributed to the sex hormones estrogen and androgen ${ }^{43}$. It has been reported that stallions have poor immune response in comparison with mare or gelding because the testosterone hormone impairs immune system functioning ${ }^{44}$. Furthermore, due to culture believe, the male horses are more preferable for pulling large wagon and horse-drawn carriage that make them more vulnerable to mosquitoes and WNV infection.

Intriguingly, the mixed breed horses showed higher seroprevalence of WNV than the Arabian and Thoroughbred horses in agreement with other earlier study ${ }^{21}$. However, different study reported no effect of breed on the seroprevalence of WNV infection in horses ${ }^{18}$. The reasons for the higher WNV seroprevalence found in our study among mixed breed horses, as compared to other breeds, is unknown but it might be due to different preference of mosquitoes to different breeds of horses, due to variables such as density of hair and differences in sweat composition ${ }^{20}$.

The limitation of the present study warrant mention is that this study is a cross-sectional study that is require a larger sample size and more geographic representation than was the case in this study and therefore to verify the associations obtained in this study, longitudinal studies are required.

\section{Conclusions}

The results of the present study confirm the circulation of WNV among horses in Egypt and provide updated information concerning the geographic area affected by the virus. Our findings strongly 
recommend intensive surveillance and implementation of effective control and prevention for male of mixed breed horses with ages $\geq 15$ years because they are at a high risk for WNV infection.

\section{Declarations}

\section{Conflicts of Interest}

The authors have no conflicts of interest to declare.

\section{Contributions}

A.S. S.K. A.A. and A.M. performed data analysis and wrote the manuscript. A.S. contributed to the sample collection and preparation. All authors have read and approved the manuscript.

\section{References}

1. Benjelloun, A., El Harrak, M. \& Belkadi, B. West Nile disease epidemiology in North-West Africa: bibliographical review. Transboundary and emerging diseases. 63, e153-e159 (2016).

2. Bunning, M. L. et al. Experimental infection of horses with West Nile virus. Emerging infectious diseases. 8, 380 (2002).

3. Engler, O. et al. European surveillance for West Nile virus in mosquito populations. International journal of environmental research and public health. 10, 4869-4895 (2013).

4. Schmidt, J. R. \& Mansoury, H. K. E. Natural and experimental infection of Egyptian equines with West Nile virus. Annals of Tropical Medicine \& Parasitology. 57, 415-427 (1963).

5. Komar, N. et al. Experimental infection of North American birds with the New York 1999 strain of West Nile virus. Emerging infectious diseases. 9, 311 (2003).

6. Rappole, J. H. \& Hubálek, Z. Migratory birds and West Nile virus. Journal of applied microbiology. 94, 47-58 (2003).

7. Niczyporuk, J., Samorek-Salamonowicz, E., Kozdrun, W. \& Mizak, Z. The survey of wild birds for West Nile virus in Poland. Polish journal of veterinary sciences14 (2011).

8. Di Sabatino, D. et al. Epidemiology of West Nile disease in Europe and in the Mediterranean Basin from 2009 to 2013. BioMed Research Internationa/2014 (2014).

9. Murgue, B., Zeller, H. \& Deubel, V. in Japanese encephalitis and West Nile viruses 195-221 (Springer, 2002).

10. Durand, B. et al. West Nile virus outbreak in horses, southern France, 2000: results of a serosurvey. Emerg. Infect. Dis. 8, 777 (2002).

11. Rainham, D. G. Ecological Complexity and West Nile Virus. Canadian Journal of Public Health. 96, 37-40 (2005). 
12. Ahmadnejad, F. et al. Spread of West Nile virus in Iran: a cross-sectional serosurvey in equines, 2008-2009. Epidemiology \& Infection. 139, 1587-1593 (2011).

13. Fleiss, J. L. Balanced incomplete block designs for inter-rater reliability studies. Appl. Psychol. Meas. 5, 105-112 (1981).

14. Pourhoseingholi, M. A., Vahedi, M. \& Rahimzadeh, M. Sample size calculation in medical studies. Gastroenterology and Hepatology from bed to bench. 6, 14 (2013).

15. Rayner, J. \& Livingston, G. The Kruskal-Wallis tests are Cochran-Mantel-Haenszel mean score tests. METRON. 78, 353-360 (2020).

16. Soliman, A. et al. Studies on West Nile virus infection in Egypt. Journal of infection and public health. 3, 54-59 (2010).

17. Taylor, R., Work, T., Hurlbut, H. \& Rizk, F. A Study of the Ecology of West Nile Virus in Egypt1. The American Journal of Tropical Medicine and Hygiene. 5, 579-620 (1956).

18. Bażanów, B. et al. A survey on West Nile and Usutu viruses in horses and birds in Poland. Viruses. 10, 87 (2018).

19. Barros, S. C. et al. West Nile virus in horses during the summer and autumn seasons of 2015 and 2016, Portugal. Veterinary microbiology. 212, 75-79 (2017).

20. Aharonson-Raz, K. et al. Spatial and temporal distribution of west Nile virus in horses in Israel (1997-2013)-From endemic to epidemics. PLoS One. 9, e113149 (2014).

21. Abutarbush, S. \& Al-Majali, A. West Nile virus infection in horses in Jordan: clinical cases, seroprevalence and risk factors. Transboundary and emerging diseases. 61, 1-6 (2014).

22. Davoust, B. et al. Serological survey of West Nile virus in domestic animals from Northwest Senegal. Vector-Borne and Zoonotic Diseases. 16, 359-361 (2016).

23. Benjelloun, A. et al. Seroprevalence of West Nile virus in horses in different Moroccan regions. Veterinary Medicine and Science. 3, 198-207 (2017).

24. Ozkul, A. et al. Concurrent occurrence of human and equine West Nile virus infections in Central Anatolia, Turkey: the first evidence for circulation of lineage 1 viruses. International Journal of Infectious Diseases. 17, e546-e551 (2013).

25. Tanner, J. M. et al. Evaluation of factors associated with positive IgM capture ELISA results in equids with clinical signs compatible with West Nile virus infection: 1,017 cases (2003). Journal of the American Veterinary Medical Association. 228, 414-421 (2006).

26. Read, M. C. Review of the epidemiological situation of West Nile virus infection in the European Union (ECDC, September 20 2011). Update (2011).

27. Reisen, W. K. et al. Overwintering of West Nile virus in southern California. Journal of medical entomology. 43, 344-355 (2014).

28. Brugueras, S. et al. Environmental drivers, climate change and emergent diseases transmitted by mosquitoes and their vectors in southern Europe: a systematic review.Environmental Research,110038(2020). 
29. Paz, S. The West Nile Virus outbreak in Israel (2000) from a new perspective: the regional impact of climate change. International journal of environmental health research. 16, 1-13 (2006).

30. Ruiz, M. O. et al. Local impact of temperature and precipitation on West Nile virus infection in Culex species mosquitoes in northeast Illinois, USA. Parasites \& vectors. 3, 19 (2010).

31. Conte, A. et al. Spatio-temporal identification of areas suitable for West Nile disease in the Mediterranean Basin and Central Europe. PloS one. 10, e0146024 (2015).

32. Hasbun, R. et al. West Nile virus retinopathy and associations with long term neurological and neurocognitive sequelae. PLoS One. 11, e0148898 (2016).

33. Weiss, D. et al. Clinical findings of West Nile virus infection in hospitalized patients, New York and New Jersey, 2000. Emerging infectious diseases 7, 654 (2001).

34. Epp, T., Waldner, C., West, K. \& Townsend, H. Factors associated with West Nile virus disease fatalities in horses. The Canadian Veterinary Journal. 48, 1137 (2007).

35. Salazar, P. et al. Outcome of equids with clinical signs of West Nile virus infection and factors associated with death. Journal of the American Veterinary Medical Association. 225, 267-274 (2004).

36. Schuler, L. A., Khaitsa, M. L., Dyer, N. W. \& Stoltenow, C. L. Evaluation of an outbreak of West Nile virus infection in horses: 569 cases (2002). Journal of the American Veterinary Medical Association. 225, 1084-1089 (2004).

37. Bullone, M. \& Lavoie, J. P. The contribution of oxidative stress and inflamm-aging in human and equine asthma. International journal of molecular sciences. 18, 2612 (2017).

38. Hernandez-Vargas, E. A. et al. Effects of aging on influenza virus infection dynamics. Journal of virology. 88, 4123-4131 (2014).

39. Montgomery, R. Age-related alterations in immune responses to West Nile virus infection. Clinical \& Experimental Immunology. 187, 26-34 (2017).

40. Balsamo, G. et al. West Nile epidemic in Louisiana in 2002. Ochsner Journal. 5, 13-15 (2003).

41. Gubler, D. J. The continuing spread of West Nile virus in the western hemisphere. Clin. Infect. Dis. 45, 1039-1046 (2007).

42. Hoffman, K. W. et al. Sex differences in cytokine production following West Nile virus infection: Implications for symptom manifestation. Pathogens and disease. 77, ftz016 (2019).

43. Kovats, S. Estrogen receptors regulate innate immune cells and signaling pathways. Cellular immunology. 294, 63-69 (2015).

44. Folstad, I. \& Karter, A. J. Parasites, bright males, and the immunocompetence handicap. Am. Nat. $139,603-622$ (1992).

\section{Figures}




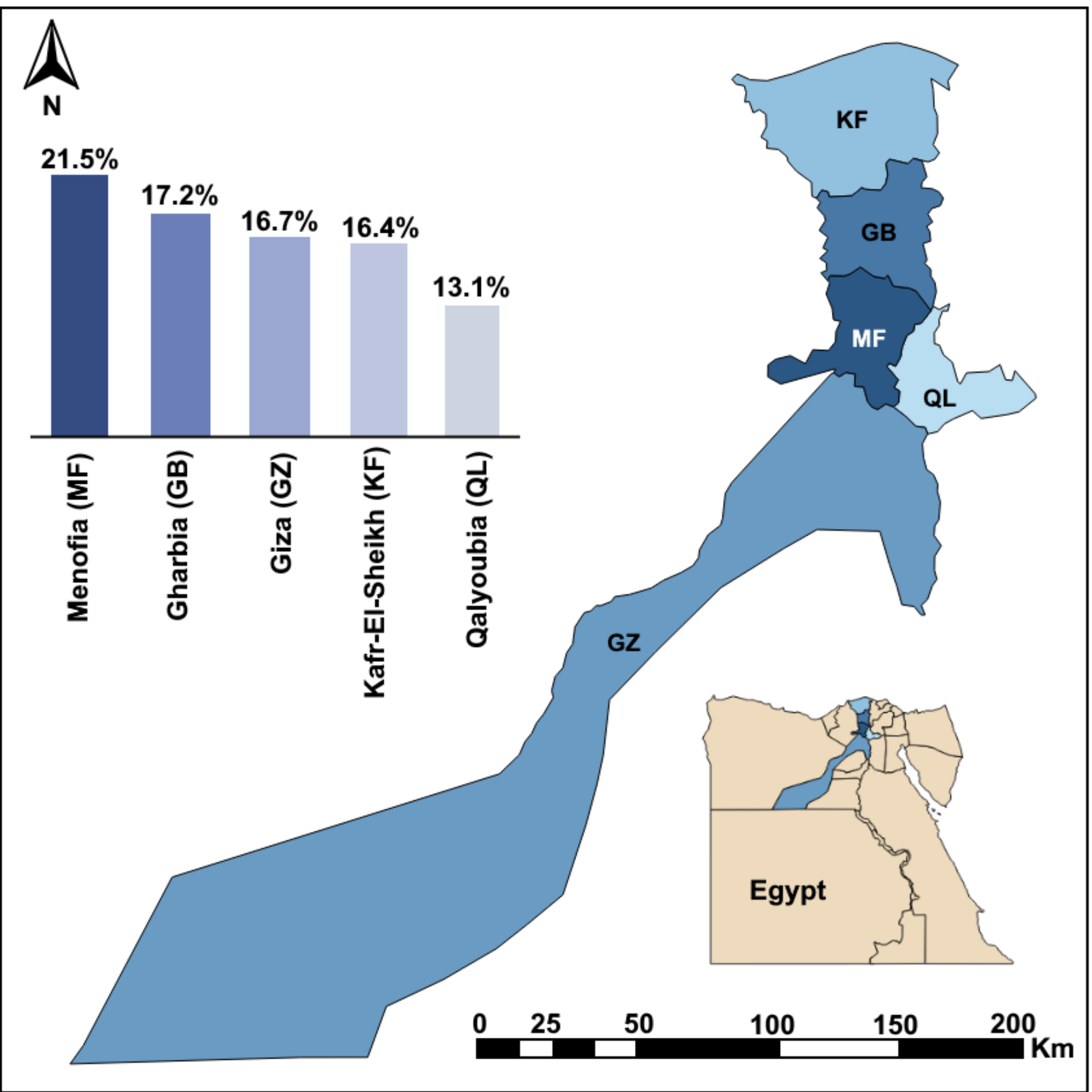

Figure 1

Geographic distribution of West Nile virus infection in horses of the Nile Delta of Egypt. Note: The designations employed and the presentation of the material on this map do not imply the expression of any opinion whatsoever on the part of Research Square concerning the legal status of any country, territory, city or area or of its authorities, or concerning the delimitation of its frontiers or boundaries. This map has been provided by the authors. 


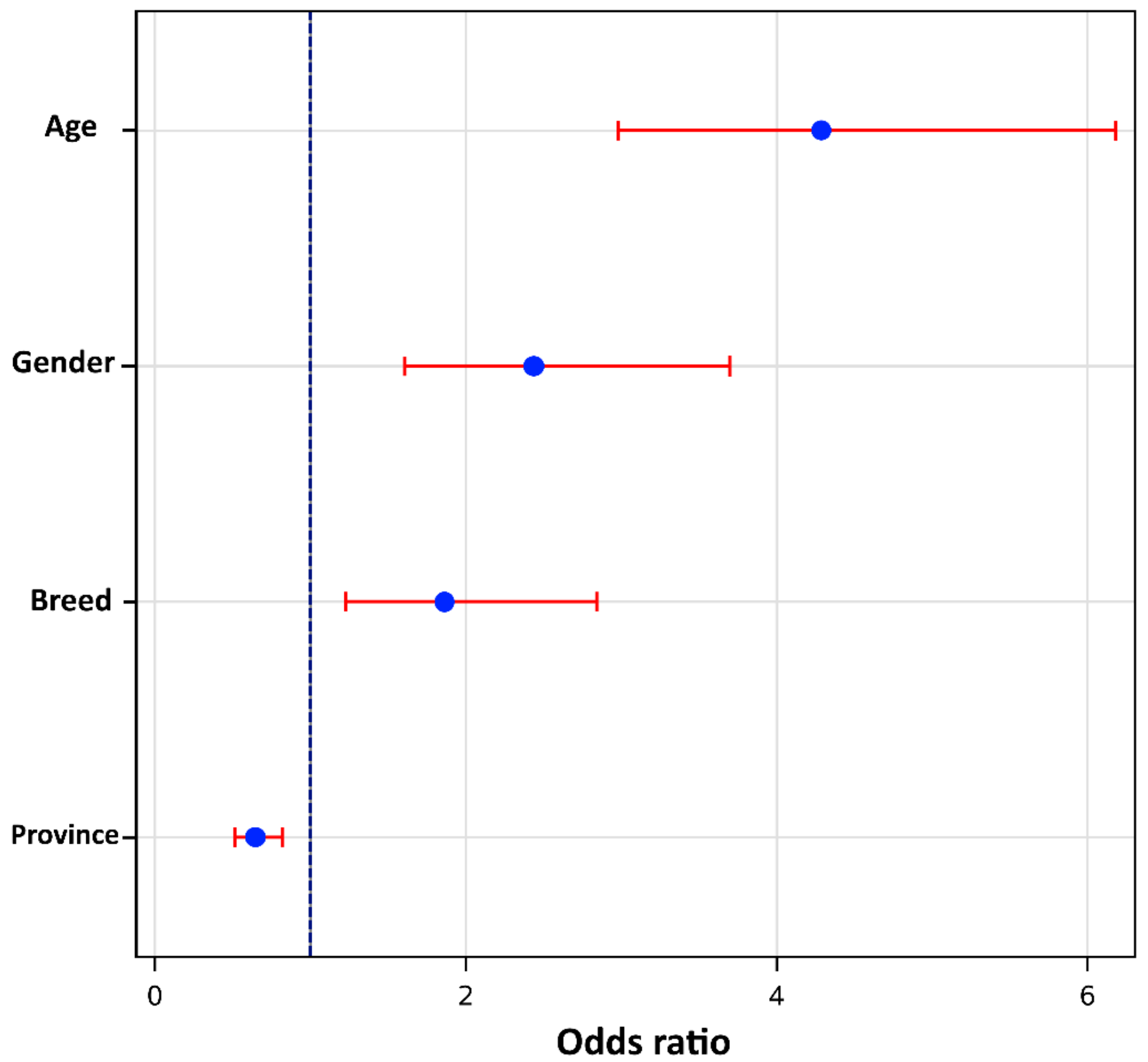

Figure 2

Odds ratio and $95 \%$ confidence interval of age, gender, breed, and geographic location to predict the seroprevalence of West Nile virus (WNV) infection in the Nile Delta horses in Egypt. The horizontal dark blue dashed line indicated odds ratio of 1 (no risk). 

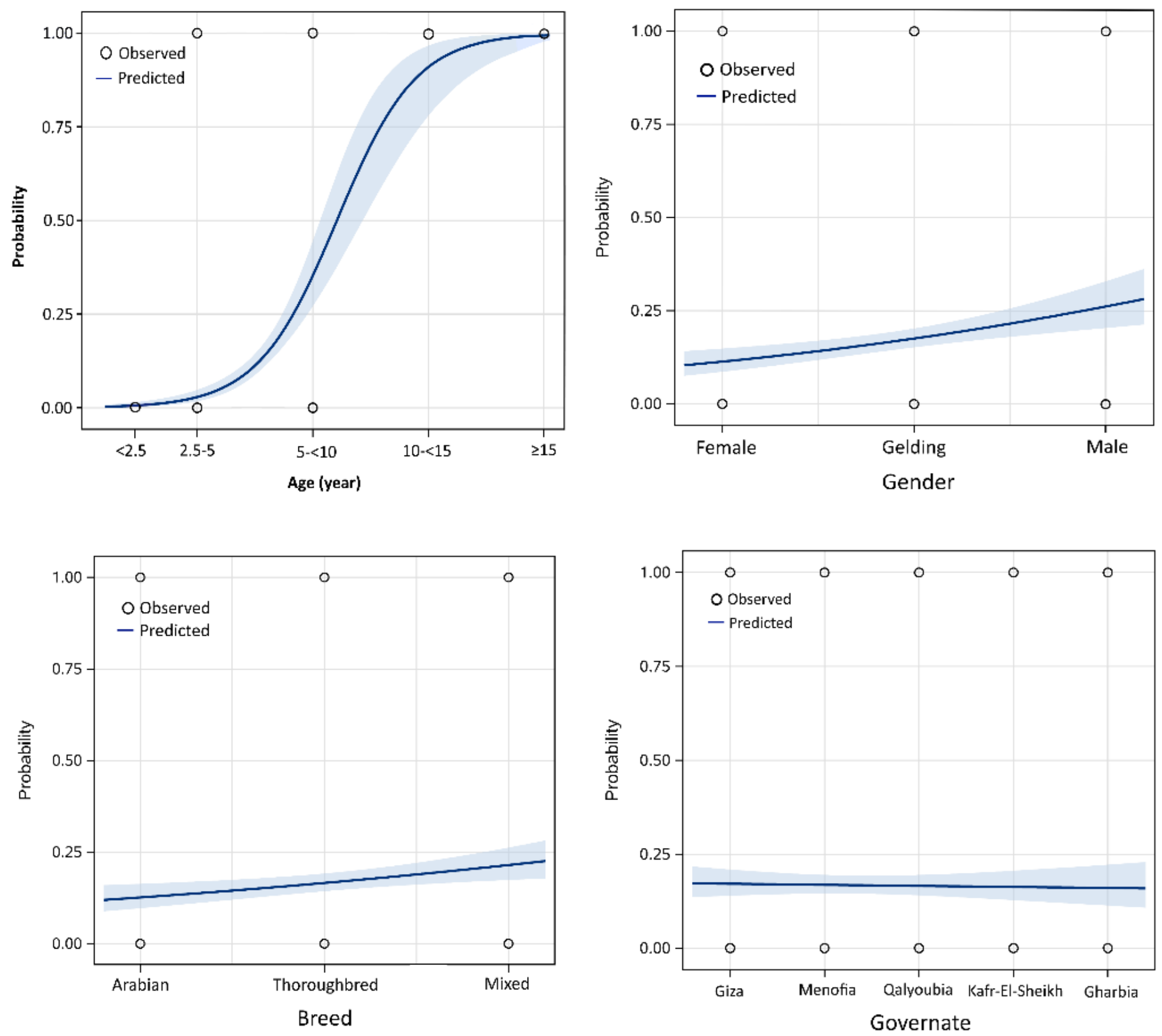

Figure 3

Probability plot for the ability of age, gender, breed, and geographic location to predict the seroprevalence of West Nile virus (WNV) infection in the Nile Delta horses in Egypt. The curve shows the likely probability of seropositive WNV associated with age, with the $95 \%$ shaded blue confidence interval 